\title{
Interactive effects of ultraviolet radiation and salinity on the ecophysiology of two Arctic red algae from shallow waters
}

\begin{abstract}
In a comparative ecophysiological study, the abundant red macroalgae Devaleraea ramentacea (L.) Guiry and Palmaria palmata (L.) O. Kuntze from shallow waters of the Arctic Kongsfjord (Spitsbergen) were exposed to hyposaline and hypersaline media, in combination with and without artificial UV radiation, to evaluate the interactive effects of both environmental parameters on optimum quantum yield of photosynthesis, as well as on the physiological capability to synthesise and accumulate photoprotective mycosporine-like amino acids (MAAs). While $D$. ramentacea exhibited euryhaline features and acclimated well to the UV radiation applied, $P$. palmata can be characterised as a stenohaline plant because of its high mortality even under mild hyposaline conditions (15 PSU). In addition, the latter species showed a limited ability to acclimate to changing PAR/UV radiation, pointing to a relatively low physiological plasticity. Both species synthesised and accumulated MAAs after UV treatment. However, only in $D$. ramentacea was a correlation between increasing MAA concentration and decreasing photosynthetic sensitivity under UV observed. All ecophysiological data from the laboratory correlate well with field observations, where both red-algal species co-exist in the same shallow-water habitat of the Kongsfjord. However, while $P$. palmata becomes more often greenish, sometimes slightly bleached over the summer months, $D$. ramentacea appears much more healthy under the prevailing environmental conditions.
\end{abstract}

U. Karsten $(\square)$

Institute of Aquatic Ecology, University of Rostock, Albert-Einstein-Strasse 3, 18051 Rostock, Germany E-mail: ulf.karsten@biologie.uni-rostock.de Fax: + 49-381-4986072

A. Dummermuth $\cdot$ K. Hoyer $\cdot$ C. Wiencke Alfred-Wegener-Institute for Polar and Marine Research, Am Handelshafen 12, 27570 Bremerhaven, Germany

\section{Introduction}

The Arctic Kongsfjord on Spitsbergen is a marine coastal ecosystem that has been intensively studied over recent years as a model for global change (Hanelt et al. 2001; Hop et al. 2002, and references therein). A typical feature of the fjord is a well-structured phytobenthic community down to a depth of almost $40 \mathrm{~m}$ (Hop et al. 2002) which plays an important role in primary production, being a food source for herbivores and detrivores, as well as a nursery area and habitat for fish and invertebrates (Lippert et al. 2001). Marine macroalgae of such high latitudes are exposed to seasonally fluctuating environmental factors such as solar radiation and temperature, as well as to long periods of ice cover (Hanelt et al. 2001; Hop et al. 2002).

Compared to the "ozone hole" over Antarctica, which has been known since the 1970s (Smith et al. 1992), the increase in ozone depletion over the Arctic represents a more recent phenomenon (see references in Wängberg et al. 1996; Rex et al. 2000; Hanelt et al. 2001). As a consequence of ozone springtime reduction in the polar regions, the UVB-radiation waveband $(280-320 \mathrm{~nm})$ rises markedly. Although the biological consequences of changes towards higher doses of UV radiation in marine ecosystems are not fully understood, many phototrophic organisms living in the intertidal, as well as in the upper subtidal, zone of the coasts are strongly affected (Franklin and Forster 1997).

The macroalgal species Devaleraea ramentacea $(\mathrm{L}$. Guiry and Palmaria palmata (L.) O. Kuntze are the most abundant Rhodophyta in the upper sublittoral of the Kongsfjord. While the first species represents one of the few endemics of the Arctic region, the latter species occurs from temperate to cold waters of the Atlantic ocean, and exhibits on Spitsbergen its northern distribution limit. In spring/summer, both organisms are often exposed to high solar radiation, and hence their photophysiology and protecting strategies to avoid or counteract UV-induced damage have been studied in 
great detail (Hanelt et al. 1997; Aguilera et al. 1999, 2002; Karsten and Wiencke 1999). From these studies, it could be concluded that $D$. ramentacea and P. palmata are capable of physiologically acclimating to diurnally changing solar radiation due to dynamic photoinhibition, i.e. the up-and-down regulation of photosynthesis in response to the respective prevailing low and high visible light, as well as UV conditions (Hanelt 1998). In addition, to prevent UV photodamage, these macroalgal species are biochemically capable of synthesising and accumulating UV-absorbing substances, the so-called mycosporine-like amino acids (MAAs) (Dunlap and Shick 1998; Karsten and Wiencke 1999; Karsten et al. 1999). As passive sunscreens, MAAs preferentially absorb UV photons in the spectral range of $310-360 \mathrm{~nm}$, followed by dissipation of the absorbed radiation energy in the form of harmless heat and fluorescence without generating photochemical reactions (Bandaranayake 1998; Cockell and Knowland 1999), and thereby protecting, at least partially, photosynthesis and growth of phototrophic organisms (Garcia-Pichel et al. 1993; Neale et al. 1998).

The motivation for the present study was the field observation that, in shallow waters of the Kongsfjord during the summer season, thalli of $P$. palmata often looked rather greenish, and sometimes slightly bleached compared to the mainly, although not always, red-coloured D. ramentacea from similar locations. Although, intuitively, radiation stress seemed to be the responsible factor, earlier results indicated a relatively high photosynthetic tolerance of $P$. palmata under increasing natural PAR and UV doses (Hanelt et al. 1997; Karsten et al. 2001). Since the large discharge of melting water into the fjord can locally and temporarily decrease the seawater salinity down to 23 PSU (Hanelt et al. 2001), and because of the fact that subtidal red algae are generally stenohaline (Kain and Norton 1990), we assumed that this abiotic factor may act as an additional stressor on the macroalgal physiology. Therefore, in a comparative ecophysiological study, we exposed $D$. ramentacea and $P$. palmata under controlled conditions on Spitsbergen to hyposaline and hypersaline media, in combination with and without artificial UV radiation, to evaluate the interactive effects of both environmental parameters on photosynthetic performance, as well as on the ability to synthesise and accumulate MAAs.

\section{Materials and methods}

\section{Algal material and study site}

The red macroalgae, D. ramentacea (L.) Guiry and P. palmata (L.) O. Kuntze, preferentially grow in shallow waters at the study site in the Kongsfjord (Ny-Alesund, Spitsbergen, $78^{\circ} 55.5^{\prime} \mathrm{N} ; 11^{\circ} 56.0^{\prime} \mathrm{E}$ ). Both species are typically attached to coarse gravel and single rocks on sandy sediments in the fjord or occur as epiphytes on rhizoids of kelps such as Laminaria saccharina (L.) Lamouroux. In the Kongsfjord, D. ramentacea typically grows in depths from $1 \mathrm{~m}$ down to $8 \mathrm{~m}$, while $P$. palmata is found slightly deeper, from $2 \mathrm{~m}$ to $10 \mathrm{~m}$. All algal samples were collected from healthy-looking, dark-red plants at $3-5 \mathrm{~m}$ by scuba-divers and kept in black bags to avoid exposure to higher solar irradiances prior to laboratory experiments, and used straight away within 1-2 h.

\section{Radiation and salinity experiments}

Thalli of both species were cut at 3-4 cm from the apical region, using a razor blade to get almost homogeneous pieces of the same age class for the exposure experiments. All plantlets were kept for $24-36 \mathrm{~h}$ in running seawater at $3-5^{\circ} \mathrm{C}$ and dim light conditions

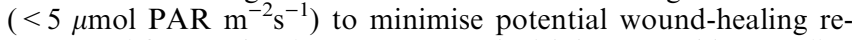
sponses. Afterwards, algae were treated with hypo- and hypersaline media, in combination with PAR and PAR + UV exposure, over a period of 4 days. Hypersaline media of 50 PSU were prepared by freezing-out fresh water from fully marine fjord water. The dilution of fjord water with MilliQ water resulted in a hyposaline solution of 15 PSU. Salinity was checked using a refractometer. All salinity treatments were carried out in 300-ml glass containers. For each salinity/radiation treatment and sampling date, two containers each with four to five thalli were used. These vessels were irradiated from the top with $30 \mu \mathrm{mol}$ PAR m ${ }^{-2} \mathrm{~s}^{-1}, 6.7 \mathrm{~W} \mathrm{~m}^{-2}$ UV-A (320$400 \mathrm{~nm})$ and $0.25 \mathrm{~W} \mathrm{~m}^{-2}$ UV-B $(280-320 \mathrm{~nm})$. Due to technical limitations on the field station, it was not possible to adjust the ratio between PAR, UV-A and UV-B to natural conditions. Therefore we accepted the application of almost realistic UV-A and UV-B radiation, in combination with much too low PAR as background irradiance. As radiation source, a combination of Philips daylight fluorescence tubes and Q-Panel UV-A-340 fluorescence tubes (Q-Panel Company, Cleveland, Ohio) were used. Radiation measurements were carried out with a Li-Cor LI-190-SB cosine-corrected sensor connected to a Li-Cor LI-1000 datalogger (Lambda Instruments, Lincoln, Neb.) for PAR, and with an RM21 broad-band UV radiometer (Dr. Gröbel, Ettlingen, Germany). While half of the containers $(15,34$ and 50 PSU) were exposed to the full radiation spectrum, the other half was kept under a specific filter foil to cut off UV-A + B (PAR treatment) (400 nm cut-off; Folex PR, Folex, Dreieich, Germany). Scattering effects were neglected. All thalli were exposed to $24 \mathrm{~h}$ PAR per day, thus reflecting Arctic summer conditions, while supplemented UV radiation was applied for only $10 \mathrm{~h}$ per day, resulting in a $10 \mathrm{~h}$ UV-treatment interval followed by a $14 \mathrm{~h}$ recovery period. Temperature was kept constant at approximately $5^{\circ} \mathrm{C}$. As a parameter to check optimum physiological performance, photosynthesis of separate thalli, i.e. true replicates, was always measured $8 \mathrm{~h}$ after on-set, as well as $7 \mathrm{~h}$ after off-set, of UV radiation. After 1, 2 and 4 days treatment with the different salinity and radiation combinations, samples for MAA analysis were taken.

\section{Photosynthesis}

After sampling, algal thalli were kept for $10-15$ min inside a lighttight box. Afterwards, photosynthetic activity was determined in this container by measuring variable chlorophyll-fluorescence of photosystem II using a portable pulse amplitude modulated fluorometer (Diving-PAM, Walz, Effeltrich, Germany). The main application of the Diving-PAM is the determination of effective PS II quantum yield by the saturation pulse method $\left(\Delta F / \mathrm{F}_{m}=\right.$ effective quantum yield of an irradiated sample, $\Delta F=\mathrm{F}_{m}-\mathrm{F}_{\mathrm{t}}$, Genty et al. 1989). However, if determined in the dark, as undertaken in the present study, the effective quantum yield equals the optimum quantum yield, which was calculated as the ratio of variable to maximum fluorescence $F_{v} / F_{m}$. Minimal fluorescence $\left(F_{o}\right)$ was measured with a pulsed measuring beam (approximately $0.3 \mu \mathrm{mol}$ photons $\left.\mathrm{m}^{-2} \mathrm{~s}^{-1}, 650 \mathrm{~nm}\right)$, followed by short pulses of saturating white light $\left(0.4-0.8 \mathrm{~s}, 1,000-5,000 \mu \mathrm{mol}\right.$ photons $\left.\mathrm{m}^{-2} \mathrm{~s}^{-1}\right)$ to record $F_{m}\left(F_{v}=F_{m}-F_{o}\right)$ (Hanelt 1998). $F_{v} / F_{m}$ values of both red algal species acclimated for $24-36 \mathrm{~h}$ to the dim light conditions in the laboratory were characteristic for photosynthetically noninhibited plants, and consequently set to $100 \%$ (= control). While 
D. ramentacea exhibited a maximum $F_{v} / F_{m}$ value of $0.65 \pm 0.02(n$ =6), P. palmata showed an $F_{v} / F_{m}$ value of $0.59 \pm 0.03(n=9)$. All data recorded are expressed in relation to the respective value.

MAA extraction and analysis

After sampling, plants were oven-dried at $50^{\circ} \mathrm{C}$, and then stored in sealed plastic bags under dry and dark conditions until analysis. Samples (4-5 replicates) of about 10-20 mg dry weight (DW) were extracted for 1.5-2 $\mathrm{h}$ in screw-capped centrifuge vials filled with $1 \mathrm{ml} \mathrm{25 \%}$ aqueous methanol (v/v), and incubated in a waterbath at $45^{\circ} \mathrm{C}$. After centrifugation at $5,000 \mathrm{~g}$ for $5 \mathrm{~min}, 700 \mu \mathrm{l}$ of the supernatants were evaporated to dryness under vacuum (Speed Vac Concentrator SVC 100H). Dried extracts were re-dissolved in $700 \mu \mathrm{l} 100 \%$ methanol and vortexed for $30 \mathrm{~s}$. After passing through a $0.2-\mu \mathrm{m}$ membrane filter, samples were analysed with a Waters HPLC system according to the method of Karsten et al. (1998a), modified as follows. MAAs were separated on a stainlesssteel Phenomenex Sphereclone RP-8 column $(5 \mu \mathrm{m}, 250 \times 4 \mathrm{~mm}$ I.D.) protected with an RP-8 guard cartridge ( $20 \times 4 \mathrm{~mm}$ I.D.). The mobile phase was $5 \%$ aqueous methanol $(\mathrm{v} / \mathrm{v})$ plus $0.1 \%$ acetic acid $(\mathrm{v} / \mathrm{v})$ in water, run isocratically at a flow rate of $0.7 \mathrm{ml} \mathrm{min} \mathrm{m}^{-1}$. MAAs were detected online with a Waters photodiode array detector at $330 \mathrm{~nm}$, and absorption spectra (290-400 nm) were recorded each second directly on the HPLC-separated peaks. Identification was done by spectra, retention time and by co-chromatography with standards extracted from the marine red macroalgae, Chondrus crispus Stackhouse (Karsten et al. 1998a) and Porphyra umbilicalis (L.) Kützing, as well as from ocular lenses of the coral trout, Plectropomus leopardus Lacepède, kindly sent by Dr. David Bellwood, James Cook University, Townsville, Australia. Quantification was done using the molar extinction coefficients given in Karsten et al. (1998b).

\section{Statistics}

Mean values and standard deviation per treatment were calculated. Statistical significance of differences in photoinhibitory response in plants kept under different salinities and radiation scenarios was tested by one-way analysis of variance (ANOVA), followed by a multi-range test using Fisher's protected least-significant difference (LSD) according to Sokal and Rohlf (1995). Calculations were done using the program InStat (GraphPad, San Diego, Calif.). To evaluate interactive effects of UV and salinity on photosynthesis, a 3-way ANOVA followed by a Tukey-Kramer posthoc test was applied using the program NCSS (Number Cruncher Statistical Systems, Kaysville, Utah).

\section{Results}

During the course of the experiment, the optimum quantum yield $\left(F_{v} / F_{m}\right)$ of the control thalli of D. ramentacea (34 PSU, PAR) always remained high, exhibiting values between 86 and $98 \%$ of the maximum, i.e. of non-inhibited plants (Fig. 1). Algae treated with 15 PSU showed a slight, but significant, decrease in $F_{v}$ $F_{m}(P<0.01)$ down to $76 \%$ of the control over the first $39 \mathrm{~h}$, followed by some recovery, resulting in values $87 \%$ of those of non-treated samples at the end of the experiment. In contrast, in plants kept at $50 \mathrm{PSU}, F_{v} / F_{m}$ showed a stronger and continuous decline to $58 \%$ of the optimum after $39 \mathrm{~h}(P>0.01)$ (Fig. 1). Afterwards, optimum quantum yield gradually increased up to $76 \%$ of the control.

$F_{v} / F_{m}$ of $D$. ramentacea treated with salinity plus UV radiation was generally much more affected compared to the salinity-only experiment (Fig. 2). Thalli kept at 15 and 34 PSU showed, at the end of the first two UVexposure intervals, a decline in optimum quantum yield down to $50-60 \%$ of the control. However, during each recovery period, $F_{v} / F_{m}$ increased to $75-80 \%$ of the maximum. In contrast, under hypersaline conditions photosynthesis was more strongly inhibited under UV (45-50\% of control; $P<0.01)$ and did not show marked recovery under PAR conditions within $48 \mathrm{~h}(P<0.01)$. However, after the last interval of the UV treatment at $50 \mathrm{PSU}, F_{v} / F_{m}$ in $D$. ramentacea was much less affected, resulting in $67 \%$ of the maximum. The final
Fig. 1 Changes in photosynthetic optimum quantum yield $\left(F_{v} / F_{m}\right)$ of Devaleraea ramentacea under various salinity conditions (15, 34, 50 PSU) and visible light $(P A R)$ over the course of $96 \mathrm{~h}$. $F_{v} / F_{m}$ of non-inhibited plants was determined as $0.65 \pm 0.02$ and standardised to $100 \%$.

Given are the mean values \pm SD $(n=10)$. Significant differences $(P<0.01)$ among samples under various salinity treatments are marked with squares: 15 PSU versus 34 PSU (white-pointed triangle), 15 PSU versus

50 PSU (white-black triangle), 34 PSU versus 50 PSU (blackpointed triangle)

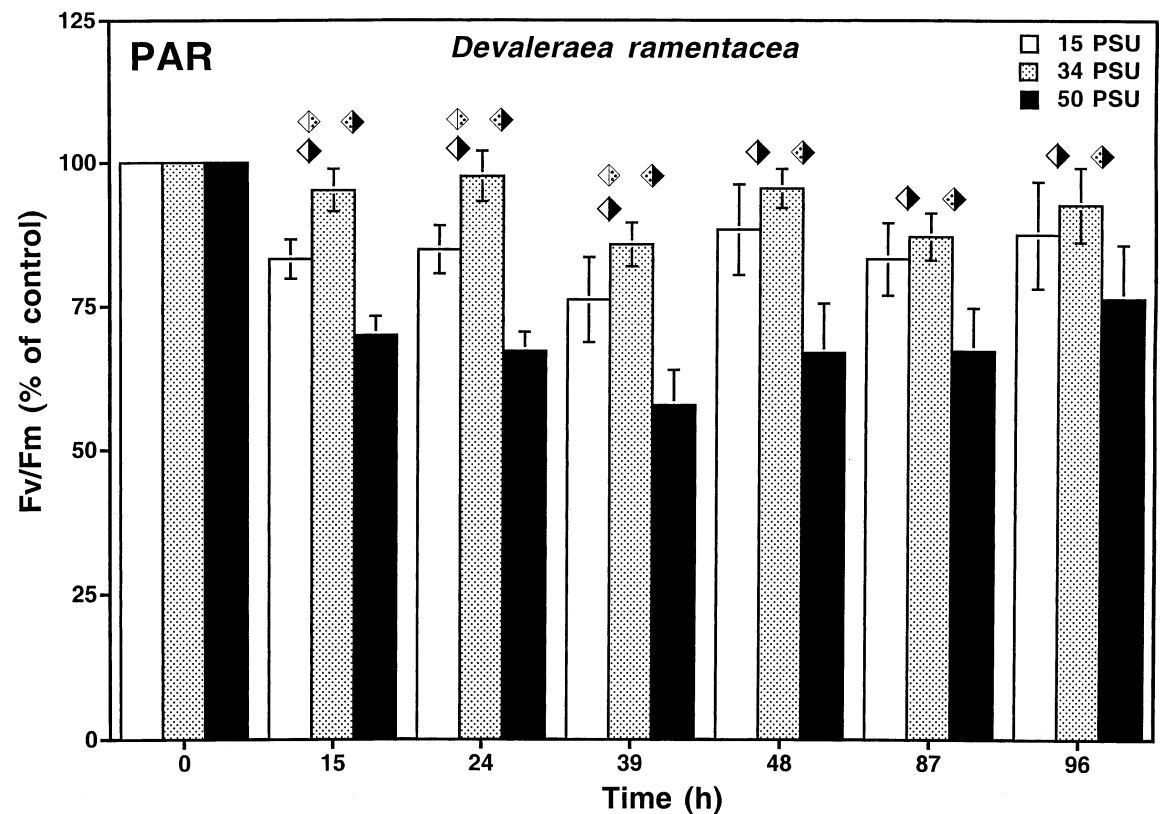


Fig. 2 Changes in photosynthetic optimum quantum yield $\left(F_{v} / F_{m}\right)$ of Devaleraea ramentacea under various salinity conditions (15, 34, 50 PSU) and ultraviolet radiation $(U V)$ over the course of 96 h. $F_{v} / F_{m}$ of non-inhibited plants was determined as $0.65 \pm 0.02$ and standardised to $100 \%$. Given are the mean values \pm SD $(n=10)$. Significant differences $(P<0.01)$ among samples under various salinity treatments are marked with squares: 15 PSU versus 34 PSU (white-pointed triangle), 15 PSU versus 50 PSU (white-black triangle), 34 PSU versus 50 PSU (black-pointed triangle). The black bars indicate the 10-h UV treatment interval followed by the 14 -h recovery period

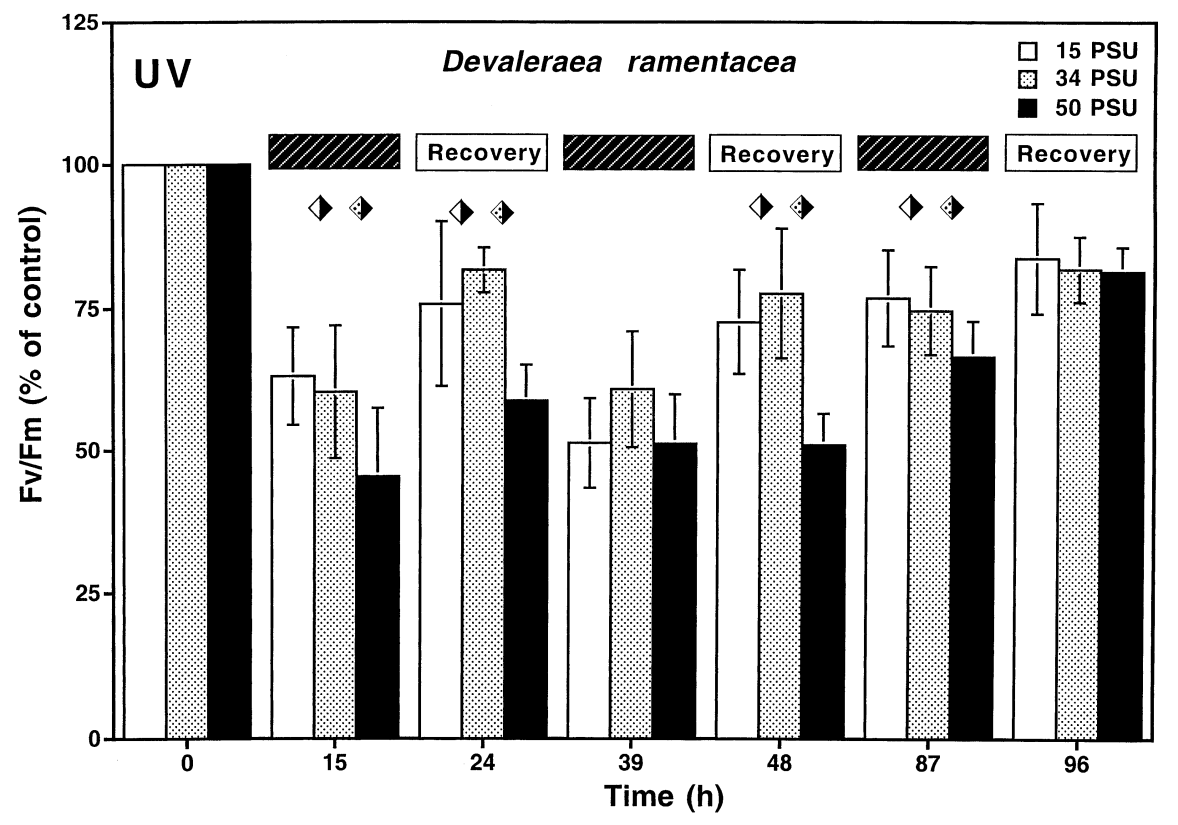

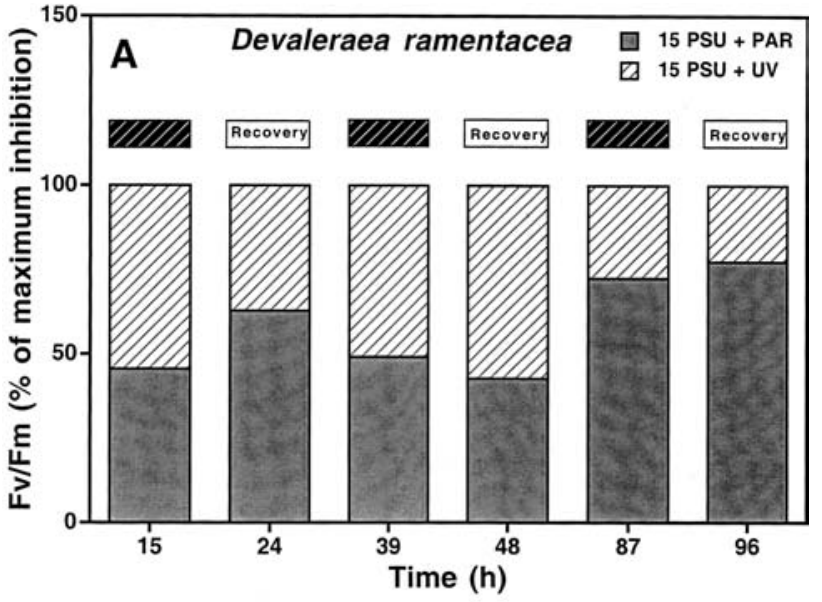

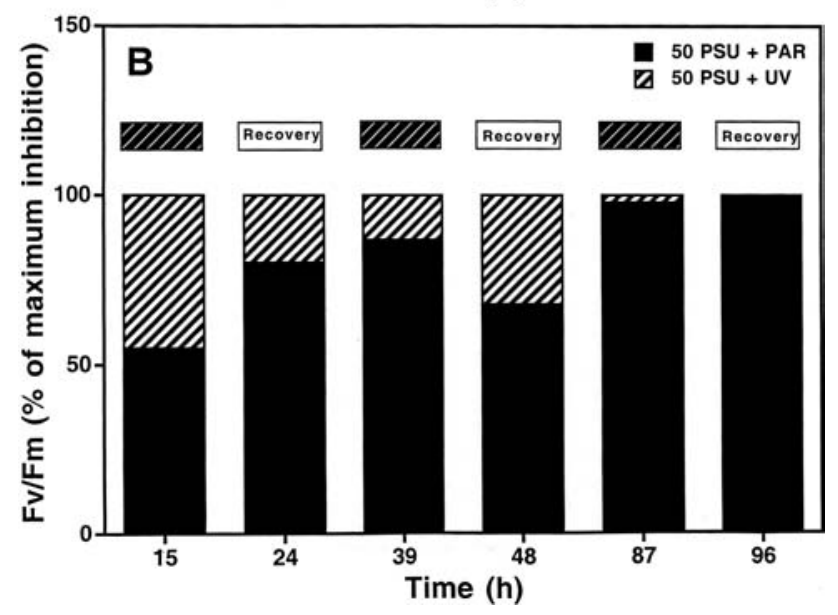

Fig. 3A, B The effect of salinity and UV treatment on the maximum decrease in the photosynthetic optimum quantum yield $\left(F_{v} / F_{m}\right)$ of Devaleraea ramentacea over the course of $96 \mathrm{~h}$. From the mean value data presented in Figs. 1 and 2, the proportional degree of photoinhibition due to both stress factors was calculated and expressed as percentage of maximum photoinhibition. A $15 \mathrm{PSU} \pm \mathrm{UV}$ treatment; B $50 \mathrm{PSU} \pm \mathrm{UV}$ treatment measurement of recovery at the end of the experiment clearly indicated for all salinities identical optimum quantum yields $>81 \%$ of the control (Fig. 2). Threeway ANOVA indicated strong interactive effects between UV and salinity in $D$. ramentacea $(P<0.001)$.

The proportional degree of photoinhibition $\left(F_{v} / F_{m}\right)$ in $D$. ramentacea due to salinity and UV treatment is shown in Fig. 3. Under hyposaline conditions over the first $48 \mathrm{~h}, 15 \mathrm{PSU}$ and UV led to nearly equal photoinhibitory responses (Fig. 3A). However, after 87 and $96 \mathrm{~h}$ exposure, the UV effect strongly decreased, resulting in only $23-28 \%$ of the total decline in optimum quantum yield. In contrast, under hypersaline conditions, the UV effect on $F_{v} / F_{m}$ in $D$. ramentacea was generally much less pronounced, and continuously decreased over the course of the experiment (Fig. 3B). After 87 and $96 \mathrm{~h}$ treatment, the salinity factor only was responsible for the observed decline in optimum quantum yield.

Seven different MAAs were detected in D. ramentacea, namely, mycosporine-glycine, shinorine, porphyra334, palythine, asterina-330, palythinol and palythene (data not shown). Porphyra-334 and palythine were the quantitatively dominating MAAs in all samples and were present in almost equimolar concentrations. Plants at the beginning of the experiment contained total MAAs of $1.2 \mathrm{mg} \mathrm{g}^{-1}$ dry weight (Fig. 4). After 1 day treatment with salinity and UV, both 15-PSU samples showed a decrease in total MAAs $\left(0.8 \mathrm{mg} \mathrm{g}^{-1} \mathrm{DW}\right)$ and both 50-PSU samples showed an increase in total MAAs $\left(1.5-1.7 \mathrm{mg} \mathrm{g}^{-1} \mathrm{DW}\right)$. MAAs in plants kept at 34 PSU with and without UV were unaffected. While after 2 days exposure, thalli at all 15-PSU and 34-PSU conditions showed unchanged total MAA concentrations, algae at both 50-PSU conditions exhibited a decrease in total MAAs $\left(1.0-1.2 \mathrm{mg} \mathrm{g}^{-1} \mathrm{DW}\right)$. A strong UVinduced increase in total MAAs (mainly due to 
Fig. 4 The interactive effects of salinity and UV treatment on the total intracellular mycosporine-like amino acid contents (MAAs) in Devaleraea ramentacea over the course of $96 \mathrm{~h}$. Given are the mean values $\pm \mathrm{SD}(n=4-5)$

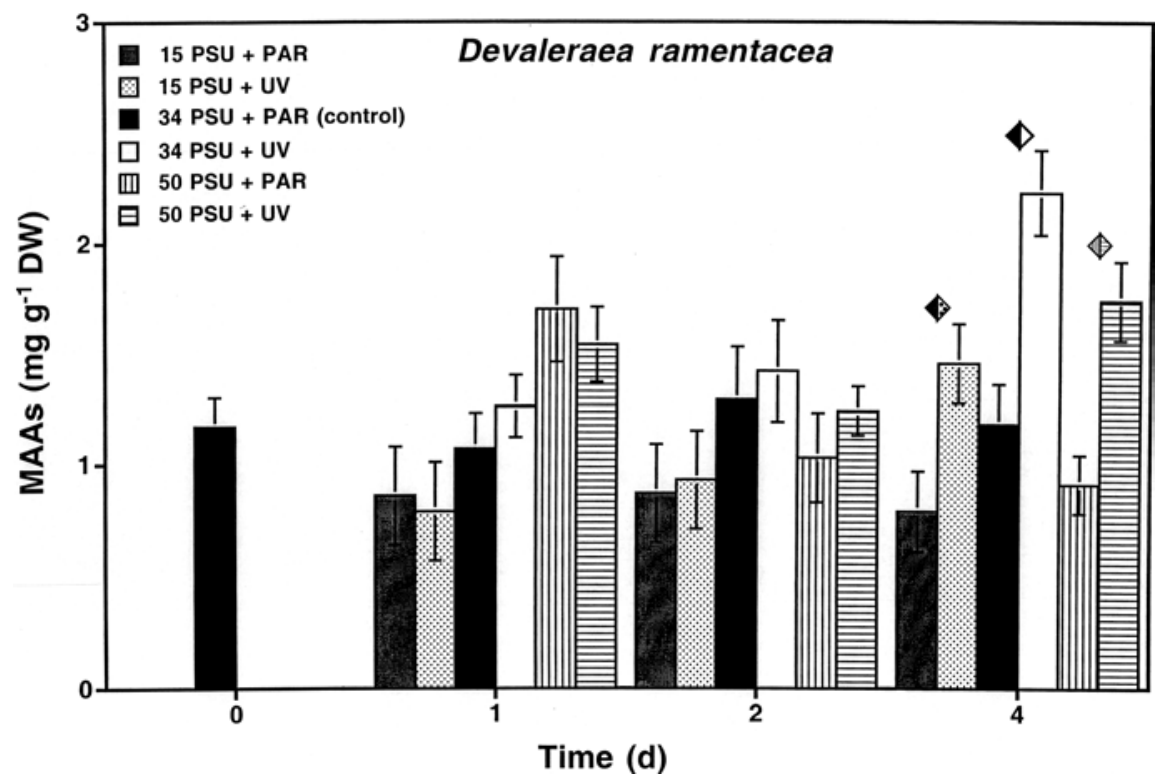

Fig. 5 Changes in photosynthetic optimum quantum yield $\left(F_{v} / F_{m}\right)$ of Palmaria palmata under various salinity conditions $(15,34$, 50 PSU) and visible light ( $P A R$ ) over the course of 96 h. $F_{v} / F_{m}$ of non-inhibited plants was determined as $0.59 \pm 0.03$ and standardised to $100 \%$. Given are the mean values \pm SD $(n=10)$. Significant differences $(P<0.01)$ among samples under various salinity treatments are marked with squares: 15 PSU versus 34 PSU (white-pointed triangle), 15 PSU versus 50 PSU (white-black triangle), 34 PSU versus 50 PSU (blackpointed triangle). Arrow indicates completely bleached (dead) thalli at 15 PSU

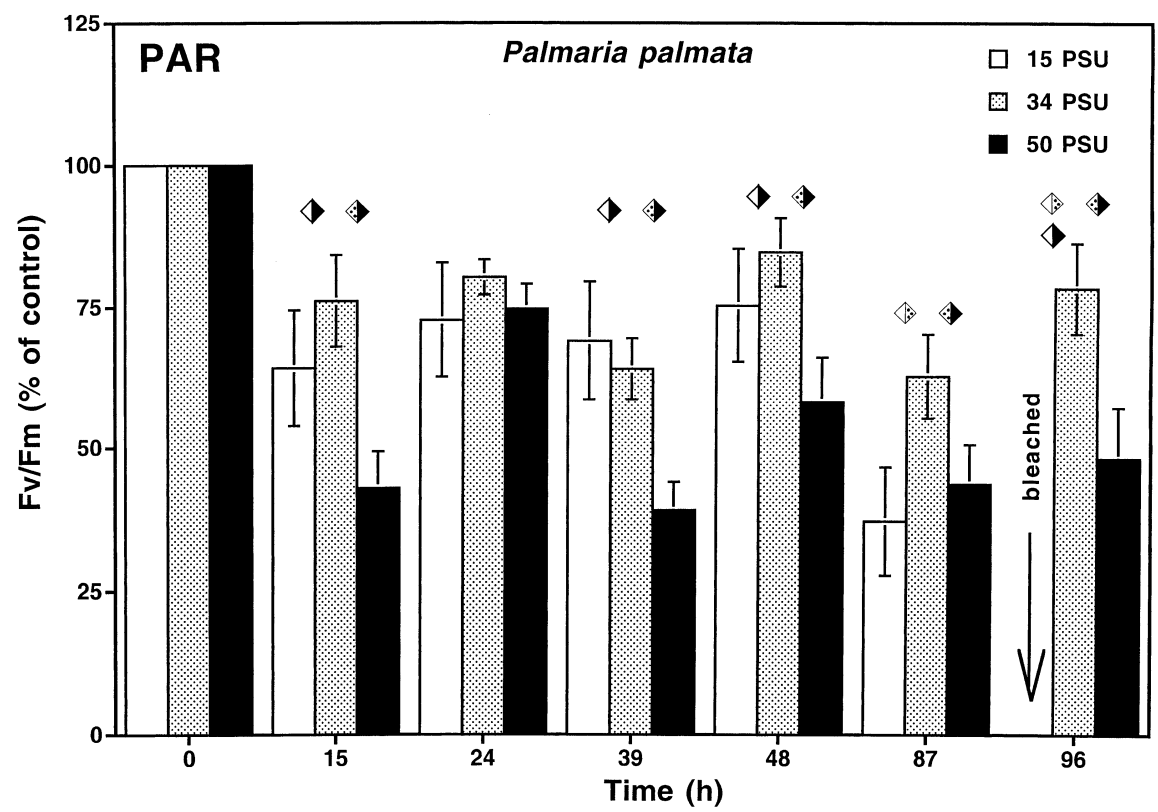

porphyra-334 and palythine) was observed at the end of the experiment. Under all salinities, UV exposure led to an almost doubling of the MAA contents. However, while at $15 \mathrm{PSU}$ and $50 \mathrm{PSU}, 1.5 \mathrm{mg}$ and $1.7 \mathrm{mg}$ MAAs $\mathrm{g}^{-1} \mathrm{DW}$, respectively, were measured in $D$. ramentacea, at 34 PSU the highest total MAA concentration of $2.2 \mathrm{mg} \mathrm{g}^{-1}$ DW was determined (Fig. 4).

While in D. ramentacea, $F_{v} / F_{m}$ under the control conditions (34 PSU, PAR) remained unchanged over the course of the experiment, in Palmaria palmata, a small, but continuous decline of this parameter was observed, resulting in $75-80 \%$ of the maximum at the end of the experimental phase (Fig. 5). Compared to D. ramentacea, the optimum quantum yield of Palmaria palmata was much more strongly affected by salinity, particularly at $50 \mathrm{PSU}$ over the first $48 \mathrm{~h}(P<0.01)$ (Fig. 5). After that period, $F_{v} / F_{m}$ in algae kept at 15 PSU also strongly declined, resulting in fully bleached and hence dead thalli at the end of the experiment. While after $96 \mathrm{~h}$ the 34-PSU samples exhibited $F_{v} / F_{m}$ values $78 \%$ of the maximum, the 50 -PSU plants showed values only $48 \%$ of the optimum (Fig. 5).

Under the salinity plus UV treatments, $F_{v} / F_{m}$ in Palmaria palmata decreased even more, indicating strong interactive effects of both abiotic factors (Fig. 6). While the 34-PSU samples always showed declining optimum quantum yields (41-54\% of the control) during on-set of UV radiation, marked recovery occurred (67-84\% of the control) after switching off the UV source. Algae incubated at 15 PSU plus UV also died 
Fig. 6 Changes in photosynthetic optimum quantum yield $\left(F_{v} / F_{m}\right)$ of Palmaria palmata under various salinity conditions $(15,34$, 50 PSU) and ultraviolet radiation $(U V)$ over the course of 96 h. $F_{v} / F_{m}$ of non-inhibited plants was determined as $0.59 \pm 0.03$ and standardised to $100 \%$. Given are the mean values $\pm \mathrm{SD}(n=10)$. Significant differences $(P<0.01)$ among samples under various salinity treatments are marked with squares: 15 PSU versus 34 PSU (white-pointed triangle), 15 PSU versus 50 PSU (white-black triangle), 34 PSU versus 50 PSU (black-pointed triangle). Arrow indicates completely bleached (dead) thalli at 15 PSU. The black bars indicate the 10-h UV treatment interval followed by the $14-\mathrm{h}$ recovery period

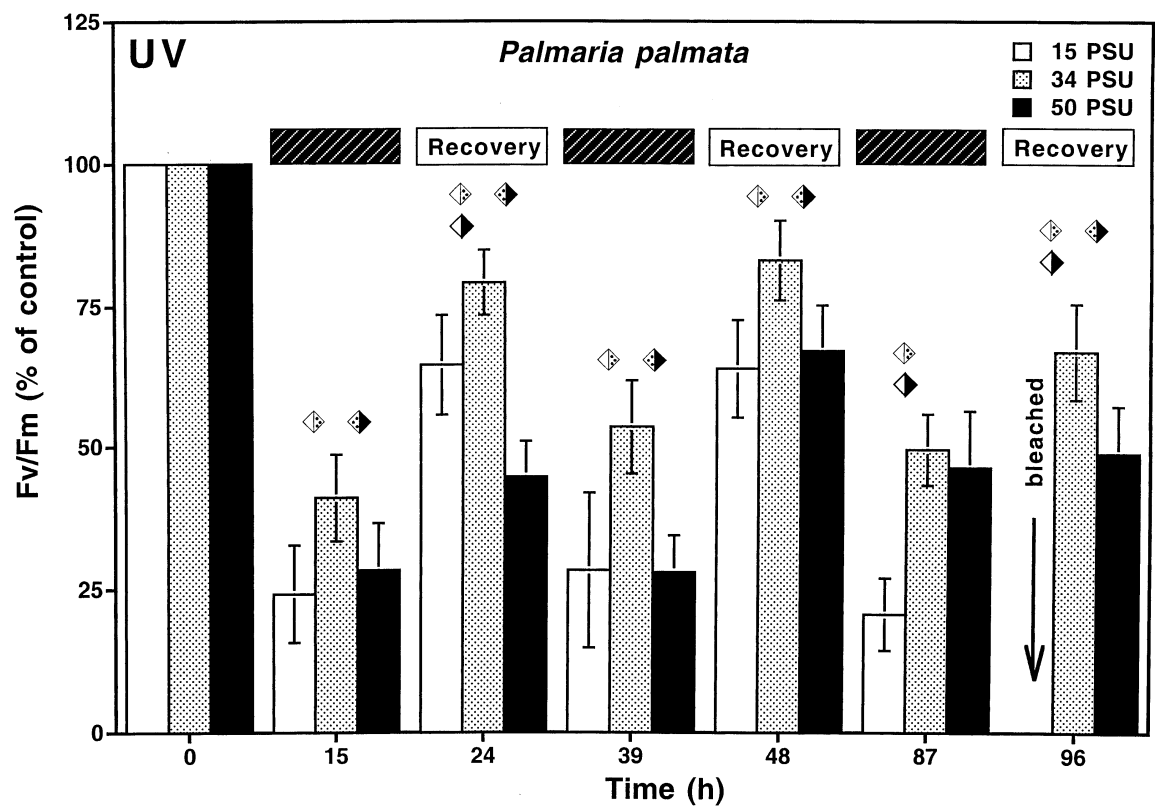

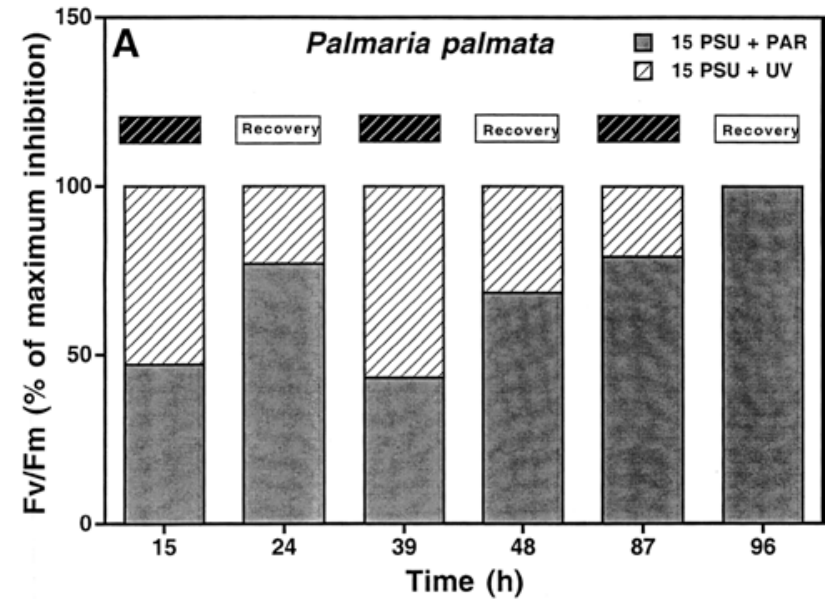

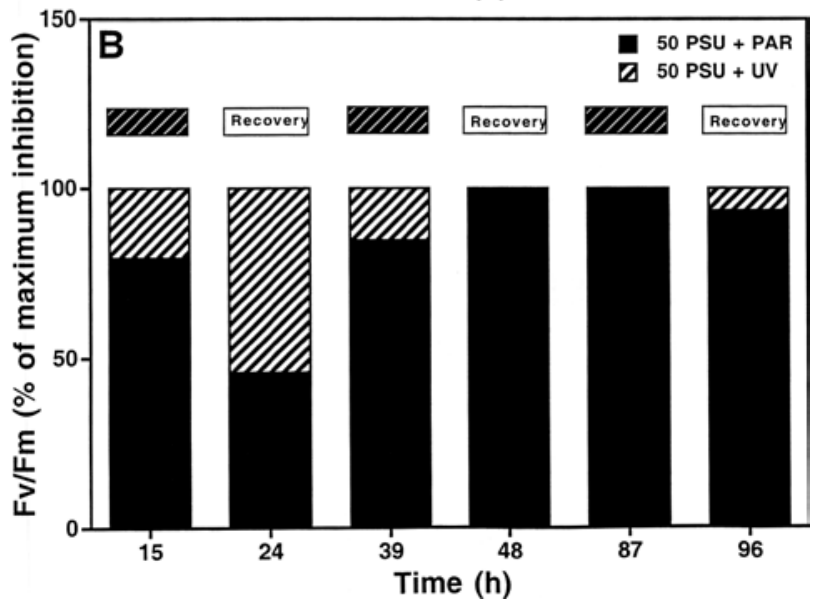

Fig. 7A, B The effect of salinity and UV treatment on the maximum decrease in the photosynthetic optimum quantum yield $\left(F_{v} / F_{m}\right)$ of Palmaria palmata over the course of $96 \mathrm{~h}$. From the mean value data presented in Figs. 1 and 2 the proportional degree of photoinhibition due to both stress factors was calculated and expressed as percentage of maximum photoinhibition. A $15 \mathrm{PSU} \pm \mathrm{UV}$ treatment; B $50 \mathrm{PSU} \pm \mathrm{UV}$ treatment after $87 \mathrm{~h}$ treatment, as indicated by completely bleached tissue (Fig. 6). Thalli of Palmaria palmata at 50 PSU plus UV exhibited, over the course of the experiment, a similar photosynthetic response compared with plants at 50 PSU without UV. Three-way ANOVA indicated strong interactive effects between UV and salinity in Palmaria palmata $(P<0.001)$.

As in $D$. ramentacea, the proportional degree of photoinhibition $\left(F_{v} / F_{m}\right)$ in Palmaria palmata due to both abiotic factors was, on average, mainly due to the salinity treatment (Fig. 7). Although at the beginning of the experiments, UV radiation also led to some decrease in optimum quantum yield, this effect got weaker after $48 \mathrm{~h}$.

In Palmaria palmata, six different MAAs were detected, namely shinorine, porphyra-334, palythine, asterina-330, palythinol and palythene (data not shown). As in D. ramentacea, porphyra-334 and palythine contributed to $>95 \%$ of total MAAs (data not shown). Plants at 34 PSU plus UV showed even after $24 \mathrm{~h}$ a small, but significant, increase in total MAA concentration $(P<0.01)$ (Fig. 8). These samples accumulated MAAs twofold over the course of the experiment. Although under hyposaline conditions, total MAAs decreased at the beginning, after $48 \mathrm{~h}$ a significant UV-induced formation could be observed $(P<0.01)$, followed by bleaching of the tissue. Under hypersaline treatment, thalli of Palmaria palmata exhibited after $48 \mathrm{~h}$ a strong accumulation of MAAs due to UV $(P<0.01)$, and after $96 \mathrm{~h}$ a decline from 2.4 to $1.9 \mathrm{mg}$ MAAs $\mathrm{g}^{-1}$ DW (Fig. 8).

\section{Discussion}

On Spitsbergen, solar radiation, as the primary environmental factor for photosynthesis and productivity of macroalgae, is not only seasonally fluctuating, but also 
Fig. 8 The interactive effects of salinity and UV treatment on the total intracellular mycosporine-like amino acid contents (MAAs) in Palmaria palmata over the course of $96 \mathrm{~h}$. Given are the mean values \pm SD $(n=4-5)$. Arrows indicate completely bleached (dead) thalli at 15 PSU

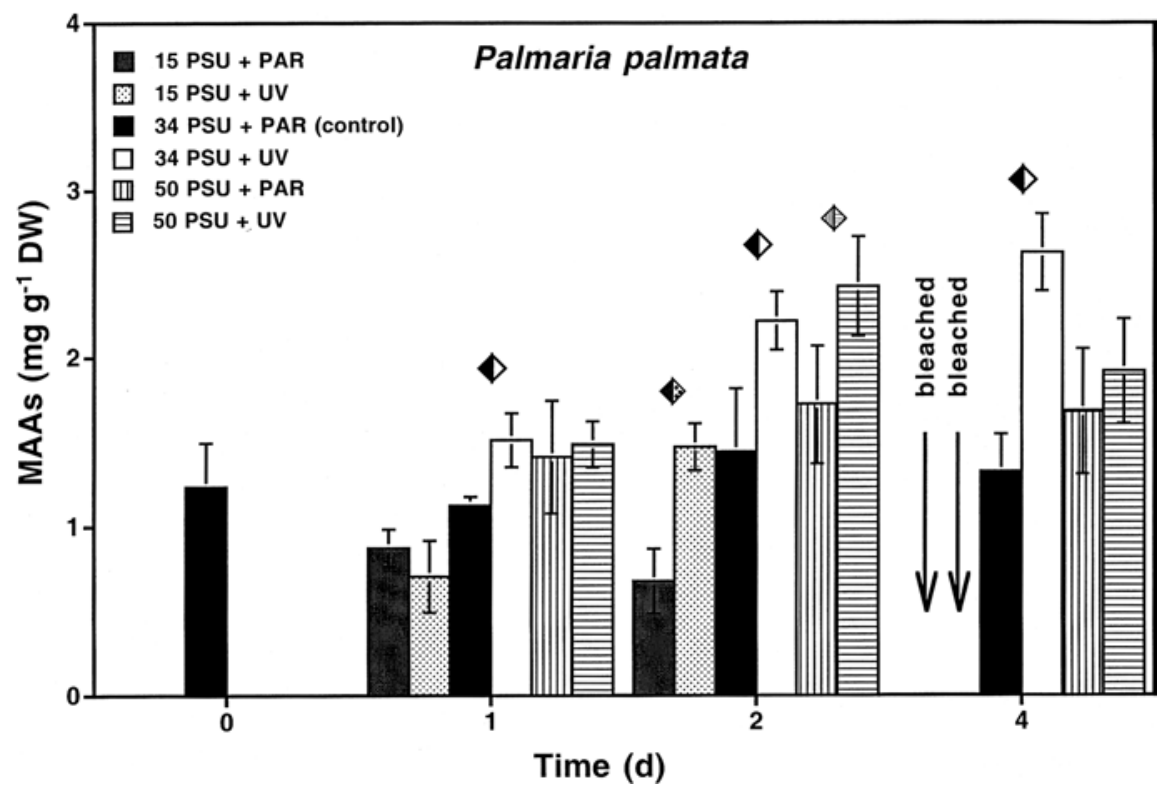

diurnally extremely variable at the earth's surface, due to rapidly changing weather conditions (Hanelt et al. 2001). In addition, during summer, the underwater light climate of the Kongsfjord is further affected by calving glaciers and strong melting-water influx, resulting in increasing turbidity due to suspended particles and, hence, a strong decrease of the water-column transmittance (Bischof et al. 1998a). The irradiance, particularly of the PAR range, to which D. ramentacea and Palmaria palmata were exposed in the laboratory, was much lower compared to nature. While, in the Arctic, typical summer insolation at the earth's surface may reach $1,300 \mu \mathrm{mol} \mathrm{m} \mathrm{m}^{-2} \mathrm{~s}^{-1}$ PAR, $19 \mathrm{Wm}^{-2} \mathrm{UV}-\mathrm{A}$ and $1.1 \mathrm{~W} \mathrm{~m}^{-2}$ UV-B (Bischof et al. 1998a), we used only $30 \mu \mathrm{mol} \mathrm{m}^{-2} \mathrm{~s}^{-1}$ PAR, $6.7 \mathrm{~W} \mathrm{~m}^{-2} \mathrm{UV}-\mathrm{A}$ and $0.25 \mathrm{~W}$ $\mathrm{m}^{-2}$ UV-B to simulate realistic underwater UV values. In spite of this experimental limitation, the data allow a comparative evaluation of photobiological responses in both species. In the water column, maximum transmittance for UV-B, as expressed by the $1 \%$ depth, ranges from 3.4 to $9 \mathrm{~m}$ (Bischof et al. 1998a). Consequently, both red-algal species may experience the UV-B irradiances applied in their natural habitat.

Macroalgae living under such fluctuating conditions need a broad physiological plasticity to acclimate to the wide range of incident solar radiation, to receive, on the one hand sufficient energy for photosynthesis, and on the other a flux low enough to avoid photodamage. Shallow-water and intertidal macroalgae are known to undergo dynamic photoinhibition when exposed to excessive sunlight that typically occurs at midday (Häder and Figueroa 1997; Hanelt 1998). Dynamic photoinhibition is considered as a photoprotective mechanism, which dissipates excessively absorbed energy as physiologically harmless thermal radiation (Osmond 1994). Previous studies have shown that the in vivo chlorophyll fluorescence of photosystem II, as used in the present investigation, is a suitable method for the evaluation of PAR- and UV-induced inhibition of photosynthesis in macroalgae (Häder and Figueroa 1997; Hanelt et al. 1997; Bischof et al. 1998b; Hanelt 1998). The optimum quantum yield $\left(F_{v} / F_{m}\right)$ was demonstrated to be a sensitive parameter to evaluate the status of the photosynthetic apparatus (Cordi et al. 1997), and hence it represents a measure of physiological performance.

The experimental set-up was designed to comparatively test the photosynthetic performance of the shallow-water species D. ramentacea and Palmaria palmata in response to UV radiation and salinity. While in the former species the strongest photoinhibitory effect was measured under hypersaline conditions without UV (25\% inhibition after 4 days), at 15 PSU only a small decrease in optimum quantum yield was observed. In strong contrast, Palmaria palmata did not survive hyposaline treatment over the course of the experiment, and also showed $50 \%$ inhibition in $F_{v} / F_{m}$ at 50 PSU. Consequently, while D. ramentacea can be characterised as a euryhaline species, Palmaria palmata exhibits rather stenohaline features. From an ecological point of view, stenohalinity with respect to growth is typical for sublittoral red algae compared to the broad salinity tolerance of intertidal species (Kain and Norton 1990). In agreement with these authors, it should be mentioned that Palmaria palmata has its main distribution in temperate/cold-temperate waters of the Northern Atlantic where it grows sublittorally in depths down to $20 \mathrm{~m}$, or protected as a typical understorey plant of kelp forests (Irvine 1983; Lüning 1990). These habitats are characterised by rather stable salinity conditions that support the development of stenohaline organisms. Consequently, the strong inhibition of photosynthesis and high mortality of the Arctic isolate of Palmaria palmata at 15 PSU can be explained by a limited physiological capacity to acclimate to external salinity fluc- 
tuations. In addition, the occurrence of this species at the northern distribution limit on Spitsbergen, which is characterised by extremely low water temperatures, may contribute to the reduced photosynthetic tolerance. Although many algal species, particularly from polar regions, are physiologically able to acclimate to lower temperatures using various adaptive mechanisms (Raven and Geider 1988; Kirst and Wiencke 1995), for example, by increasing enzyme content to compensate for lower activity, this response depends on the degree of temperature decrease. Since the temperate Palmaria palmata grows at Spitsbergen at its distribution limit, it may be speculated that the primary metabolism under such, for this species, extreme cold conditions is just functioning and hence most probably slowed down according the Q10-rule. Consequently, all acclimation responses would be affected as well. This hypothesis is supported by the fact that temperature optima for photosynthesis and growth are only, in endemic Antarctic macroalgae, significantly lower compared to Arctic and cold-temperate species, which typically exhibit strong decline of both processes with decreasing temperatures (Healey 1972; Wiencke et al. 1993, 1994; Kirst and Wiencke 1995). While many Antarctic seaweeds seem to be relatively strongly adapted, Arctic and cold-temperate counterparts show a much weaker adaptation to low temperatures, and hence the general physiological performance may be species specifically more or less affected. Although Palmaria palmata is abundant in the Kongsfjord, the data presented, in combination with the observation of rather greenish, sometimes slightly bleached, thalli during summer in the field, indicate stressed plants. However, the interactive effects of salinity and temperature should still be experimentally evaluated.

Although salinities in the upper layers of the water column do not generally decline to values lower than 23 PSU (Hanelt et al. 2001), it should be mentioned that 15 PSU, as tested in the present study, represents a mild hyposaline stress for marine organisms (Kirst 1990). In contrast to Palmaria palmata, many other red macroalgae from intertidal, as well as sublittoral, habitats grow well or even preferentially, and photosynthesise at this salinity (Bird et al. 1979; Kirst 1990; Mostaert et al. 1995).

When UV radiation was applied on top of the salinity treatment, both species studied initially exhibited similar photosynthetic responses, i.e. a decline of the optimum quantum yield after on-set of UV followed by some degree of recovery after switching off the UV. While UV-induced photoinhibition compared to the control was relatively small in $D$. ramentacea, Palmaria palmata exhibited a much stronger response (Figs. 2, 6). In addition, the former species showed an increasing UV tolerance of photosynthesis over the course of the experiment, while the latter species seemed unable to photoacclimate. This confirms the data of Hanelt (1998) who showed that photosynthesis of Palmaria palmata collected along a depth profile in the Kongsfjord did not acclimate to the prevailing radiation gradient. Within other macroalgal species from the Arctic and Antarctica, the degree of photoinhibition is normally a function of the collecting depth, i.e. shallow-water isolates are more PAR/UV resistant than plants from deeper waters (Bischof et al. 1998a, 1998b). The difference in the acclimation potential of the photosynthetic performance between D. ramentacea and Palmaria palmata under UV is reflected by the vertical distribution in the Kongsfjord, since the former species grows in shallower waters. In addition, at more temperate locations, Palmaria palmata preferentially inhabits deeper waters than in the Arctic and hence the shallow-water growth habit in the Kongsfjord appears unusual. Due to incomplete osmotic adjustment, both algae may be better able to tolerate an increase in UV radiation as compared to salinity change.

In recent studies, the photobiological function of MAAs as a cellular defence system against the harmful effects of UV radiation on growth, photosynthesis and other processes has been reported for various marine phototrophic organisms (Garcia-Pichel et al. 1993; Dunlap and Shick 1998; Neale et al. 1998). In a convincing bio-assay, Adams and Shick (1996) documented experimentally that UV-treated, and subsequently fertilised, sea-urchin eggs typically show a UV-dose-dependent delay in the first cell division, compared to unirradiated eggs from the same batch. The determination of the cleavage delay in eggs having different MAA contents, produced by feeding adults different macroalgal diets (with high and low MAA levels) in the absence of UV, proved to be a perfect indicator for the sunscreen function of these compounds. The authors documented that the greater the MAA concentration in the eggs, the less they were affected by UV radiation. In the present study, both D. ramentacea and Palmaria palmata synthesised and accumulated MAAs over the course of the experiment in response to the UV treatment, except for those samples treated with 15 PSU. The highest MAA concentrations were usually measured at 34 PSU (Figs. 4, 8). The UV-induction data for MAAs are well supported by earlier experiments in the field, where both species were transplanted in the Kongsfjord from deeper waters to the surface, followed by exposure to natural full, as well as filtered, solar radiation (Karsten and Wiencke 1999; Karsten et al. 1999). However, the most striking fact is that, although both $D$. ramentacea and Palmaria palmata form MAAs in a similar manner and concentration, this increase correlates well with the rising photosynthetic tolerance under UV only in the former species. In Palmaria palmata, the optimum quantum yield under UV does not seem to benefit from higher MAA contents. These contradictionary results on the potential sunscreen function of MAAs in both red algae clearly indicate species-specific physiological advantages are not solely due to the synthesis and accumulation of UV-absorbing compounds.

In conclusion, while $D$. ramentacea is able to resist different environmental stress factors in the upper 
sublittoral of the Arctic Kongsfjord, indicating a relatively high degree of physiological plasticity, Palmaria palmata exhibits a marked sensitivity against salinity and a limited capabilty to acclimate to changing PAR/ UV radiation, pointing to a rather inflexible metabolism.

Acknowledgements The authors would like to thank Heike Lippert, Eva Philipp and Stefan Kremb for providing field samples, and the Ny-Ålesund International Research and Monitoring Facility for their support. This project was financially supported by the Deutsche Forschungsgemeinschaft (Ka 899/3-1/2) and the German Research Minister (BMBF) (project MONA-03F0229).

\section{References}

Adams NL, Shick JM (1996) Mycosporine-like amino acids provide protection against ultraviolet radiation in eggs of the green sea urchin Strongylocentrotus droebachiensis. Photochem Photobiol 64:149-158

Aguilera J, Karsten U, Lippert H, Vögele B, Philipp E, Hanelt D, Wiencke C (1999) Effects of solar radiation on growth, photosynthesis and respiration of marine macroalgae from the Arctic. Mar Ecol Prog Ser 191:109-119

Aguilera J, Dummermuth A, Karsten U, Schriek R, Wiencke C (2002) Enzymatic defences against photooxidative stress induced by ultraviolet radiation in Arctic marine macroalgae. Polar Biol 25:432-441

Bandaranayake WM (1998) Mycosporines: are they nature's sunscreens? Nat Prod Rep 15:159-172

Bird NL, Chen LCM, McLachlan M (1979) Effects of temperature, light and salinity on growth in culture of Chondrus crispus, Furcellaria lumbricalis, Gracilaria tikvahiae (Gigartinales, Rhodophyta), and Fucus serratus (Fucales, Phaeophyta). Bot Mar 22:521-527

Bischof K, Hanelt D, Karsten U, Brouwer P, Tüg H, Wiencke C (1998a) Acclimation of brown algal photosynthesis to penetration of light and ultraviolet radiation in Arctic coastal waters (Kongsfjord, Spitsbergen). Polar Biol 20:388-395

Bischof K, Hanelt D, Wiencke C (1998b) UV-radiation can affect depth-zonation of Antarctic macroalgae. Mar Biol 131:597-605

Cockell CS, Knowland J (1999) Ultraviolet radiation screening compounds. Biol Rev 74:311-345

Cordi B, Depledge MH, Price DN, Salter LF, Donkin ME (1997) Evaluation of chlorophyll fluorescence, in vivo spectrophotometric pigment absorption and ion leakage as biomarkers of UV-B exposure in marine macroalgae. Mar Biol 130:41-49

Dunlap WC, Shick MJ (1998) Ultraviolet radiation-absorbing mycosporine-like amino acids in coral reef organisms: a biochemical and environmental perspective. J Phycol 34:418430

Franklin LA, Forster RM (1997) The changing irradiance environment: consequences for marine macrophyte physiology, productivity and ecology. Eur J Phycol 32:207-232

Garcia-Pichel F, Wingard CE, Castenholz RW (1993) Evidence regarding the UV sunscreen role of a mycosporine-like compound in the cyanobacterium Gloeocapsa sp. Appl Environ Microbiol 59:170-176

Genty B, Briantais JM, Baker NR (1989) The relationship between the quantum yield of photosynthetic electron transport and quenching of chlorophyll fluorescence. Biochim Biophys Acta 990:87-92

Häder DP, Figueroa FL (1997) Photophysiology of marine macroalgae. Photochem Photobiol 66:1-14

Hanelt D (1998) Capability of dynamic photoinhibition in Arctic macroalgae is related to their depth distribution. Mar Biol 131:361-369
Hanelt D, Wiencke C, Nultsch W (1997) Influence of UV radiation on the photosynthesis of Arctic macroalgae in the field. J Photochem Photobiol B Biol 30:179-187

Hanelt D, Tüg H, Bischof K, Groß C, Lippert H, Sawall T, Wiencke C (2001) Light regime in an Arctic fjord: a study related to stratospheric ozone depletion as a basis for determination of UV effects on algal growth. Mar Biol 138:649-658

Healey FP (1972) Photosynthesis and respiration of some Arctic seaweeds. Phycologia 11:267-271

Hop H, Pearson T, Hegseth EN, Kovacs KM, Wiencke C, Kwasniewski S, Eiane K, Mehlum F, Gulliksen B, WlodarskaKowalczuk M, Lydersen C, Weslawski JM, Cochrane S, Gabrielsen GW, Leakey R, Lönne OJ, Zajaczkowski M, FalkPetersen S, Kendall M, Wängberg SA, Bischof K, Voronkov AY, Kovaltchouk NA, Wiktor J, Poltermann M, Prisco G di, Papucci C, Gerland S (2002) The marine ecosystem of Kongsfjorden, Svalbard. Polar Res 21:167-208

Irvine LM (1983) Seaweeds of the British Isles, vol 1. Rhodophyta. British Museum, London

Kain JM, Norton TA (1990) Marine ecology. In: Cole KM, Sheath RG (eds) Biology of the red algae. Cambridge University Press, Cambridge, pp 377-422

Karsten U, Wiencke C (1999) Factors controlling the formation of UV-absorbing mycosporine-like amino acids in the marine red alga Palmaria palmata from Spitsbergen (Norway). J Plant Physiol 155:407-415

Karsten U, Franklin LA, Lüning K, Wiencke C (1998a) Natural ultraviolet and photosynthetic active radiation induce formation of mycosporine-like amino acids in the marine macroalga Chondrus crispus (Rhodophyta). Planta 205:257-262

Karsten U, Sawall T, Wiencke C (1998b) A survey of the distribution of UV-absorbing substances in tropical macroalgae. Phycol Res 46:271-279

Karsten U, Bischof K, Hanelt D, Tüg H, Wiencke C (1999) The effect of ultraviolet radiation on photosynthesis and ultraviolet-absorbing substances in the endemic Arctic macroalga Devaleraea ramentacea (Rhodophyta). Physiol Plant 105:5866

Karsten U, Bischof K, Wiencke C (2001) Photosynthetic performance of Arctic macroalgae after transplantation from deep to shallow waters followed by exposure to natural solar radiation. Oecologia 127:11-20

Kirst GO (1990) Salinity tolerance of eukaryotic marine algae. Annu Rev Plant Physiol Plant Mol Biol 41:21-53

Kirst GO, Wiencke C (1995) Ecophysiology of polar algae. J Phycol 31:181-199

Lippert H, Iken K, Rachor E, Wiencke C (2001) Epifauna associated with macroalgae in the Kongsfjord. Polar Biol 24:512522

Lüning K (1990) Seaweeds: their environment, biogeography, and ecophysiology. Wiley, New York

Mostaert AS, Karsten U, King RJ (1995) Physiological responses of Caloglossa leprieurii (Ceramiales, Rhodophyta) to salinity stress. Phycol Res 43:215-222

Neale PJ, Banaszak AT, Jarriel CR (1998) Ultraviolet sunscreens in Gymnodinium sanguineum (Dinophyceae): mycosporine-like amino acids protect against inhibition of photosynthesis. J Phycol 34:928-938

Osmond CB (1994) What is photoinhibition? Some insights from comparisons of shade and sun plants. In: Baker NR, Bowyer JR (eds) Photoinhibition of photosynthesis. From the molecular mechanisms to the field. BIOS Scientific Publications, Oxford, pp 1-24

Raven JA, Geider RJ (1988) Temperature and algal growth. New Phytol 110:441-461

Rex M, Dethloff K, Handorf D, Herber A, Lehmann R, Neuber $\mathrm{R}$, Notholt J, Rinke A, Gathen $\mathrm{P}$ von der, Weisheimer A, Gernandt H (2000) Arctic and Antarctic ozone layer observations - chemical and dynamical aspects of variability and long-term changes in the polar stratosphere. Polar Res 19:193204 
Smith RC, Prezelin BB, Baker KS, Bidigare RR, Boucher NP, Coley T, Karentz D, MacIntyre S, Matlick HA, Menzies D, Ondrusek M, Wan Z, Waters KJ (1992) Ozone depletion: ultraviolet radiation and phytoplankton biology in Antarctic waters. Science 255:952-959

Sokal RR, Rohlf FJ (1995) Biometry. The principle and practice of statistics in biological research. Freeman, New York

Wängberg SA, Selmer JS, Ekelund NGA, Gustavson K (1996) UVB effects on nordic marine ecosystem. Tema Nord 1996. Nordic Council of Ministers, Copenhagen
Wiencke C, Rahmel J, Karsten U, Weykam G, Kirst GO (1993) Photosynthesis of marine macroalgae from Antarctica: light and temperature requirements. Bot Acta 106:78-87

Wiencke C, Bartsch I, Bischoff B, Peters AF, Breeman AM (1994) Temperature requirements and biogeography of Antarctic, Arctic and amphiequatorial seaweeds. Bot Mar 37:247-259 